\title{
Fiç̧ão Científica: uma narrativa da subjetividade homem-máquina
}

Fátima Rcgis do Olivcira*

\section{RESUMO}

As novas tecnologias de informaçāo e a comunicação mediada por computador desafiam as fronteiras modernas que definiam o humano como sujeito natural, pensante e autônomo. Ao violar essas fronteiras, as novas tecnologias produzem seres híbridos e mundos possiveis, antes restritos às narrativas de ficção cientifica. Partindo das interrogações como a ficção cientifica conquistou a Atualidade e como nos tornamos ciborgues, o artigo desenvolve duas hipóteses complementares. A primeira aposta que a ficção cientifica é uma narrativa que problematiza as fronteiras entre subjetividade, tecnociência e espaço-tempo como estratégia de interrogar o humano. A segunda hipótese crê que ao pôr em questão as fronteiras ontológicas e epistemológicas modernas, as novas tecnologias permitiram os hibridismos que atualizam o ciborgue como devir humano e elegem a fiç̧āo cientifica como ficçāo da Atualidade.

\section{ABSTRACT}

The new informational technologies and the computer mediated communication defy the boundaries of Modernity that had defined the human as a natural, thinking and autonomous subject. Fading the manmachine boundaries, the new technologies have enabled the creation of hybrid creatures and possible worlds, previously restricted to the science fiction genre. Starting from the questions how science fiction conquered the contemporary and how we became cyborgs, this article analyses two complementary hypothesis. The first one maintains that science fiction is a narrative that questions the boundaries separating subjectivity, technoscience and space-time as a strategy to question the human issue. The second one asserts that by questioning the ontological and cpistemological boundaries, the new technologies give rise to the cyborg as the beconing of man and elect science fiction as the fiction of Today.

\footnotetext{
* Doutora em Comunicação (ECO/UFRJ). Professora do Departamento de Relaçōes Públicas da UERJ
} 
$\mathrm{Na}$ virada do século XX para o XXI assistimos a um fato curioso: os monstros e os mundos possíveis da ficção científica parecem escapar das páginas de livros e telas de cinema e se materializar em nossos laboratórios. O rato com orelha humana nas costas, o computador enxadrista Deep Blue, o canadense Steve Mann - o cyberman,' o ciberespaço e a realidade virtual são alguns exemplos. Esses seres e mundos híbridos, frutos das tecnologias de informação e da comunicação mediada por computador, indicam a perda de nitidez nas fronteiras modernas entre orgânico/maquínico, natural/artificial, físico/não-físico, corpo/mente, factual/ficcional produzindo dois eixos de problematizações que interessam a este artigo. O primeiro eixo refere-se às mudanças dos conceitos e relações entre humanos e técnica que nos faz repensar as fronteiras ontológicas e epistemológicas modernas. O segundo remete ao fato de os seres e mundos híbridos parecerem personagens e paisagens da ficção científica, o que desperta a curiosidade por entender como o termo híbrido ficção científica tomou-se tão adequado para descrever o contexto cultural e científico da Atualidade.

No primeiro eixo, mais especificamente no campo das fronteiras ontológicas, percebemos deslocamentos nos conceitos de humano, de técnica e de espacialidade. Alguns exemplos esclarecem estas mudanças. A biologia, ao descobrir o funcionamento do código genético e o modo como a informação se processa a nível molecular, mudou o estatuto do ser vivo, inaugurando uma série de estudos em diversas áreas que tem produzido uma maquinação bioquímica do humano. Por sua vez, hoje, os dispositivos tecnológicos não são apenas ferramentas, próteses ou extensões para os sentidos. Eles modulam nossas capacidades físicas, sensoriais e cognitivas, reconfigurando as fronteiras e os modos de interação entre homens e máquinas. Já o ciberespaço e a realidade virtual oferecem a possibilidade de experimentar fisicamente mundos materiais e abstratos, espaços naturais e construídos, ampliando o campo da experiência de espacialidade.

As tecnologias de informação proporcionam também novas formas de intervenção e conhecimento do mundo, problematizando assim as fronteiras epistemológicas modernas. Ao produzir clones e seres híbridos, as biotecnologias e a engenharia genética permitem que o homem atue sobre os mecanismos da vida: até então fora do alcance da ciência. Questões como a criação de seres clonados e híbridos, que antes preocupavam apenas os autores de ficção científica, tornam-se algumas das indagações éticas, científicas e filosóficas mais relevantes na Atualidade, o que nos conduz ao segundo eixo de problematizações.

Filósofos e cientistas contemporâneos, ao discutir as articulações entre tecnologia, subjetividade e experiências possíveis, têm convergido para temas e elementos estéticos da ficção cientifica, evidenciando o curto-circuito entre factual e ficcional na Atualidade. Entusiasmado com os avanços na prática 
de imersão virtual, o cientista do MIT (Instituto de Tecnologia de Massachusetts), Hans Paul Moravec, analisa em seu livro de divulgação cientifica Mind Children (1988, p. 109) a possibilidade de transmigrar a mente humana para a memória do computador. ${ }^{2} \mathrm{Da}$ mesma forma, pensadores como Katherine Hayles (1999) e Bruce Mazlish (1993) utilizam indistintamente textos acadêmicos e narrativas de fiç̧ão científica como fontes de referência para construir seus argumentos filosóficos. O momento presente se vê como fiç̧ão científica. $O$ fato tem sido observado por acadêmicos e escritores do gênero. Marshall MacLuhan constata: "Nós vivemos ficção científica" (Apud BUKATMAN, 1998, p. 6). O escritor J.G. Ballard percebe que "Nós anexamos o futuro ao nosso próprio presente" (Idem).

Neste novo cenário de ficção científica, o humano passa a ser entendido como um ser em continuidade com animais e máquinas. O ciborgue - figura híbrida de animal e máquina, habitante de mundos naturais e construídos, ponto de interseção entre realidade e ficção - é a figura que melhor incorpora as complexas questões do humano em suas novas conexões com o mundo. Este novo devir humano desafia de modo inquietante o sujeito natural, pensante e autônomo forjado na Modernidade. Para examinar as novas relações entre humanos e tecnologias duas questões parecem fundamentais. A primeira interroga a mudança no conceito de humano e tenta compreender como nos tornamos ciborgues? A segunda investiga por que a Atualidade se vê como ficção científica? Dito de outro modo: Como a ficção científica, considerada um gênero menor, restrito a fãs, conquistou o presente? Ou simplesmente: como a ficção científica conquistou a Atualidade?

O objetivo deste artigo é mostrar que a história de como nos tornamos ciborgues baseia-se nas mesmas violações de fronteiras da trama sobre como a fiç̧ão cientifica conquistou a Atualidade. O entrelaçamento inextricável destas duas questões conduz as investigações sobre $o$ que é o humano hoje. Duas hipóteses complementares orientam o estudo. A primeira aposta que a ficção científica é uma narrativa que problematiza as fronteiras entre subjetividade, tecnociência e espaço-tempo como estratégia de interrogar o humano. A segunda indica que ao pôr em questão as fronteiras ontológicas e epistemológicas modernas, as novas tecnologias de comunicação e de informação fazem surgir o ciborgue como novo devir do humano e elegem a fição cientifica como a fiç̧ão da Atualidade.

A estratégia para estabelecer a singularidade da mudança no conceito de humano é a historicidade. Propor a historicidade como modo de investigação é supor que o humano é um conceito construido cultural e historicamente a partir de desafios, invenções, encontros, oportunidades e transformações surgidas em cada momento histórico. Para pensar o lugar do humano hoje é necessário que se realize um recuo ao passado recente a fim de entender, de modo muito breve, como foi construído o conceito de humano na Modernidade. 


\section{Modernidade: Subjetividade, Tecnociencia E Futuro}

No decorrer dos séculos XVII e XVIII, o sucesso da produção de artefatos e das invenções científicas legitimam a razão como método verídico de conhecimento, conferindo profundidade subjetiva, autonomia e secularidade ao humano. ${ }^{3} \mathrm{O}$ pensamento iluminista considera que, como ser dotado de razão, o homem deve ser capaz de administrar a si próprio e a sociedade, sem a tutela de um ser superior e a crença em ilusões (emancipação da religião e do mito). Para tanto, a objetividade das ciências puras ou exatas deve servir de modelo para as ciências humanas e sociais nascentes promoverem o processo de educação civilizatória, ou seja, a passagem do mito à razão, da barbárie à civilização. No início do século XIX, é corrente a idéia de que o homem precisa superar seus instintos animais para alcançar o ideal de sujeito presente a si, auto-suficiente, racional e possuidor de livre arbítrio. Esta mesma racionalidade deve ser aplicada aos processos sociais, políticos e econômicos a fim de promover as mudanças necessárias à criação de organizações sociais democráticas e livres no futuro. A divisão epistêmica entre ciências puras e ciências humanas funda também a separação ontológica entre homens, animais e máquinas na Modernidade. Os animais pertencem à natureza. Os humanos são seres entre a natureza (locus de força, pureza, perfeição e animalidade) e a cultura (lugar de razão e civilização), devendo superar a animalidade em prol da civilização. E, por fim, os produtos da técnica são meros instrumentos inertes, produzidos pela cultura para realizar a mediação entre natureza e cultura.

Gestada em berço iluminista, a Revolução Francesa consolida a força do indivíduo e a confiança na razão, propondo que: nós (indivíduos, cidadãos) podemos mudar a sociedade. Já a Revolução Industrial mostra o potencial da expansão técnica como instrumento que pode ajudar a emancipar o individuo ou submetê-lo à dominação. $O$ futuro é o lugar da realização do sujeito e da sociedade: Utopia Moderna.

Não é apenas o conceito de homem como sujeito singular, pensante e autônomo que emerge do humanismo moderno. Ao combinar a profundidade de subjetividade do humano, o uso da técnica para mudar a sociedade, e o sonho de novos espaços (utopia $=$ u-topos $=$ um outro lugar) em um tempo futuro, o pensamento moderno cria também as condições de surgimento da ficção científica. Vamos primeiro buscar compreender a ascensão da fiç̧ão científica na Atualidade e depois nos dedicaremos às mudanças nas relações homem/técnica que culminarão no ciborgue.

\section{Como A Ficção Científica Conquistou A Atualidade}

No século XIX a ficção científica ganha popularidade com as histórias de Júlio Verne, H. G. Wells e Edward Bellamy. Em 1929 surge o nome ficção científica. Considerada literatura menor, suas narrativas dirigem-se a públicos 
especificos, verdadeiras seitas que abrigam editores, escritores e fãs. Classificada como produto da cultura de massa, na primeira metade do século $\mathrm{XX}$ a ficção cientifica não merece a atenção de estudos acadêmicos. Apesar disso, escritores e editores buscam circunscrever um campo teórico para o gênero: o cunho educativo e a afinidade com o progresso são destacados por Hugo Gernsback - o editor da primeira revista dedicada exclusivamente à ficção científica, a Amazing Stories (Apud Clute e Nicholls, 1995, p. 311); o pesquisador $J$. O Bailey enfatiza a familiaridade do gênero com as ciências teórico-experimentais (Id, p. 312). A partir do movimento New Wave (década de 1960), as abordagens teóricas sobre a ficção científica escapam das propostas simplificadoras que a reduziam ao caráter científico e buscam compreender e aprofundar as interfaces entre ciência, tecnologia, humanos e sociedade, sob a égide das ciências teórico-experimentais e das ciências humanas e sociais. Surgem os termos ficção científica hard e soft. Frederik Pohl (1997, p. 7), citando Tom Shippey, oferece um conceito bem mais amplo: propõe que ficção científica refere-se a mudanças (no homem, na História, na cultura, no tempo, entre outros). Estudos recentes de alguns pesquisadores norte-americanos têm privilegiado a articulação entre a sociedade e as mudanças tecnológicas, enquanto outros pesquisadores e escritores do gênero defendem que o âmago da ficção científica reside nas imbricações entre subjetividade e tecnociência. O escritor Norman Spinrad define ironicamente: "fiç̧ão científica é qualquer coisa publicada como ficção cientifica"(Apud SMITH, 1982, p. 9).

Mas, por que uma forma de narrativa tão facilmente reconhecida por seus icones (espaçonaves, seres extraterrestres, robôs, supercomputadores, planetas longínquos, viagens no tempo e a lugares exóticos ou inexplorados, histórias alternativas e humanos com superpoderes) insiste em escapar dos aportes teóricos mais inclusivos? Certamente todos esses icones referem-se a perspectivas trazidas pelo desenvolvimento científico e tecnológico. Referem-se também a mudanças: no espaço, no tempo, no homem e em seu modo de perceber e atuar sobre a realidade. Associam desenvolvimento tecnológico a novas experiências do sujeito e, conseqüentemente, novas formas de organizações sociais. O desafio que se apresenta é investigar uma abordagem para a ficção cientifica sem privá-la de sua complexidade ou reduzir sua multiplicidade temática. Procuremos buscar mais pistas por meio da investigação da árvore genealógica da ficção cientifica e das condições modernas que produziram seu nascimento.

As ficções fantásticas (a ficção científica e sua irmã, a fantasia) são herdeiras das fábulas e das narrativas de viagens. As fábulas descrevem seres maravilhosos e lugares exóticos. Seu objetivo, diz Asimov, é o mesmo da ficção científica: "descrever a vida tal como não a conhecemos" (ASIMOV, 1984, p. 120). A justaposição entre o conhecido e o estranho, o Eu e o Outro, 
o existente e o não-existente, revela que o tema comum à fábula, ficção cientifica e fantasia é a interrogação de nossa humanidade e de nosso mundo a partir da presença de um Outro ser (pigmeus e trogloditas, alienigenas e robôs, ou duendes e ogros) ou de um Outro mundo (as culturas orientais, os planetas longinquos, os reinos de fadas). E é claro que as viagens realizadas e os seres visitados (ou criados) dependem do potencial de saber (mágico, religioso ou científico) de cada cultura. A partir de uma ou várias mudanças nas esferas de subjetividade, saber e espaço-tempo, a fábula e a ficção fantástica exercitam a curiosidade e o deslumbramento sobre seres e mundos desconhecidos como estratégia de problematização de nossa própria humanidade e de nosso potencial de exploração no mundo. Por exemplo, o monstro do Dr. Frankenstein (Cf. SHELLEY, s/d) e as criaturas do Dr. Moreau (Cf. WELLS, 1989) afrontam os limites do humano tanto em relação à sua constituição biológica quanto em relação à sua capacidade de intervir sobre a criação de vida; já a máquina do tempo, do clássico homônimo de H. G Wells (Cf. WELLS, 1989), desafia o determinismo das leis da fisica. Não é casual que o nascimento da ficção científica tenha se dado no alvorecer da Revolução Industrial, na Inglaterra. $O$ sujeito autônomo e singular, legitimado pelo desenvolvimento tecnocientífico, e a idéia de futuro como produto das mudanças realizadas no presente fornecem o terreno fértil para a narrativa de ficção científica.

A Modernidade fornece as condições de nascimento da ficção científica, mas não pode pensá-la. Ao erigir fronteiras entre homens, animais e máquinas, 182 a epistemologia moderna trata a tecnologia como instrumento de alienação ou libertação do indivíduo, mas nunca como algo que se imbrica com os modos de subjetivação e faz repensar os limites do humano. A Modernidade não apenas propicia as condições de aparecimento da ficção científica quanto ela mesma é uma narrativa: uma metanarrativa. O pensamento esclarecido também sonhou com um outro ser - o sujeito civilizado e emancipado - e um outro mundo - a sociedade democrática no futuro. $O$ ailleurs moderno é um espaço a ser construído num tempo futuro. As mudanças sonhadas pelos modernos - a emancipação do homem pela razão, a construção de organizações sociais democráticas e o controle da natureza pela ciência - eram uma narrativa única e linear. Enquanto pensadores e cientistas buscam as condições de concretização da Utopia Moderna por meio da antecipação do futuro, os escritores de fiçãa cientifica narram as outras utopias, distopias e heterotopias possibilitadas pelos deslocamentos de fronteiras nos campos da subjetividade, tecnociência e configurações de espaço e tempo. Surgem histórias sobre viagens no tempo, aventuras em planetas distantes, novas tecnologias de transporte (balões e submarinos) e de comunicação (rádio), máquinas inteligentes, experimentos biológicos com animais e homens, entre outros temas. 
A ficção científica enevoa os limites entre ciências humanas, sociais e teórico-experimentais, doando a suas narrativas o caráter múltiplo da experiência. Daí sua dificuldade de ser apreendida pela epistemologia moderna. A multiplicidade que a ficção científica atribui à experiência só é possivel de ser compreendida por procedimentos transdisciplinares. Para tanto, resgato dois conceitos de dois pensadores do século XX que buscaram entender o caráter múltiplo do homem e do mundo. De Michel Foucault tomo emprestado o exercício da curiosidade como estratégia de interrogar o pensamento por meio de um saber que lhe é estranho (1984, p. 13). De Gilles Deleuze retomo o empirismo filosófico necessário para produzir inesgotáveis aquis e agoras (1988, p. 17-8). A curiosidade de Foucault e o empirismo de Deleuze provocam mudanças de perspectivas, características da abordagem transdisciplinar. $\mathrm{O}$ deslocamento de si mesmo e do pensamento permite que se vislumbrem as multiplicidades, os devires, as diversas possibilidades do humano e do mundo. Acredito que em suas narrativas, a ficção científica exercita a tarefa filosófica de interrogar os modos do homem ser e atuar sobre o mundo por meio de duas práticas científicas - a curiosidade e o experimentalismo. A ficção científica cria as condições de produção de sentido entre subjetividade, tecnociência e espaço-tempo, tornando-se campo propício para interrogar o humano por meio da comunicação fecunda entre filosofia e ciência. ${ }^{5}$

O momento presente caracteriza-se pela expansão mundial da tecnologia e pelo esmaecimento de fronteiras que têm propiciado novas condições de produção de subjetividade, novas configurações espaço-temporais para a experiência humana e novas relações com a tecnologia. Por reconfigurar as possibilidades de experiência dos homens e do mundo, a sociedade atual gera uma abertura para as multiplicidades, para fazer habitar o humano no inumano, a ficção no real e vice-versa. A ficção científica, como o gênero que investiga os modos de produção de subjetividade em uma sociedade tecnocientífica, parece tornar-se a ficção da atualidade, ganhando respeitabilidade no mundo acadêmico.

\section{Como Nos Tornamos Ciborgues}

O ciborgue parece ser a figura que melhor problematiza a relação homemmáquina hoje. Embora a idéia de ciborgue date da primeira metade do século $\mathrm{XX}$, as raizes históricas da relação homem-máquina são bem anteriores. Ao contrário do que possa parecer à primeira vista, a relação homem-máquina não incorpora apenas as questões de definição do humano e da técnica, refere-se também à capacidade de intervenção do homem sobre os mecanismos da vida e da realidade. 


\section{Nossos outros (I): autômatos e robôs}

As figuras que mais diretamente problematizam a relação entre homens e suas máquinas são os autômatos - engenhos mecânicos capazes de gerar seu próprio movimento - e os seres animados pelas mãos humanas ou divinas. A criação de vida artificial tem raízes remotas na História e na imaginação da humanidade. Desde a Antiguidade o homem tem construído, na realidade e na ficção, autômatos e figuras animadas "artificialmente". O relógio Clepsidra, as donzelas de ouro do deus Hefestos, a estátua de Pigmalião, o Golem, o Pato de Vaucanson, o menino artista de Pierre Jacquet-Droz ${ }^{6}$ são alguns exemplos.

$\mathrm{Na}$ ficção do século XIX, as figuras mecânicas que mimetizam seres humanos são vistas como blasfêmias abomináveis e trazem desgraças para seus criadores. Um bom exemplo é $O$ homem de areia (1816), de E.T.A Hoffman. Neste conto, o professor Spalanzani é condenado judicialmente por ter apresentado Olímpia - uma boneca de madeira animada por segredos alquímicos - como sua filha legítima e tê-la inserido no convívio social. Considerado por muitos o primeiro romance de ficção científica, Frankenstein (1817), de Mary Shelley, é a primeira história em que matéria inerte é animada por meio de procedimentos científicos. $\mathrm{Na}$ experiência do trágico $\mathrm{Dr}$. Frankenstein repousam algumas das principais questões sobre as relações entre homens e autômatos: a promessa de obtenção da força prometéica, o medo de que o conhecimento sobre a criação da vida seja proibido e leve o homem à ruína, o receio de que a criatura se volte contra seu criador, e o temor de que a criatura se reproduza por conta própria.

Em Ojogador de xadrez de Maelzel (1836), Edgar Allan Poe (POE, 1981) conta a história sobre o que parecia ser a maior invenção de sua época: o Autômato Jogador de Xadrez. O conto não é uma ficção científica. $O$ autômato enxadrista existiu e derrotou Napoleão II em um torneio de xadrez. Determinado a desmascarar o autômato, Poe dedica-se ao problema de como diferenciar um robô de um humano, com base na máxima "perfeição versus falha humana". Com uma narrativa detetivesca, o texto de Poe apresenta, já no século XIX, a questão da inteligência artificial. Descartes (1996, p.111-2) estabeleceu dois critérios de diferenciação entre homens e autômatos: a capacidade de dar respostas a situações inusitadas e a habilidade de agir pelo conhecimento (que implica a constituição de cadeias de razões, baseadas nas idéias claras e distintas). Ambos os critérios implicam o uso da representação, conferido pela alma racional. O 'Deep Blue' de Poe, entretanto, demonstra possuir capacidade de representar e inteligência aguçada. Fiel ao pensamento majoritário de sua época, Poe rejeita a hipótese de que a máquina possa desenvolver as faculdades da mente humana, e decide que só pode haver um anão no interior da caixa. Sua solução é correta. Pouco tempo depois a fraude é revelada: um anão no interior da máquina movimenta as peças no tabuleiro. 
A primeira obra importante do século XX a tratar a questão da vida artificial foi a peça teatral R.U.R. (Rossum's Universal Robots), escrita em 1920 pelo tcheco Karel Capek ( $\mathrm{s} / \mathrm{d}$ ). Metáfora da mecanização dos operários nas fábricas, R.U.R. apresenta de modo pujante o temor de que nossas criações nos superem. O cientista Rossum incorpora o desejo de controle do mundo natural ao criar vida por meio de um processo "mais simples, flexivel e rápido que ainda não ocorreu à natureza". Em R.U.R., enquanto os robôs são superiores aos humanos em força física e inteligência, não representam ameaça. Quando são modificados e exibem comportamentos e sentimentos humanos, fogem ao controle. Eis o perigo: se nossas máquinas forem idênticas a nós em natureza e grau, elas agirão exatamente como nós, humanos: tomando o lugar cio Criador e as rédeas sobre os outros seres vivos do planeta.

Nas primeiras décadas do século XX, os sentimentos ambivalentes em relação aos robôs prevaleceram nas narrativas de ficção científica. No periodo que os teóricos do gênero classificam como Golden Age (1938-1950), a balança começa a pender favoravelmente aos robôs. Isaac Asimov foi um dos maiores defensores da causa dos robôs. Sua maior preocupação era demonstrar a segurança e a fidelidade dos robôs em relação aos humanos. Os robôs de Asimov são dotados de cérebros positrônicos compatíveis com o pensamento e a fala dos humanos. As famosas "Três Leis da Robótica" agem sobre os robôs de forma semelhante às normas de conduta disciplinares: com o objetivo de estancar os atos indesejáveis à vida social. Entretanto, as Três Leis - de caráter moral - freqüentemente entram em conflito com o raciocínio lógicoformal do robô. Eles se tornam confusos. Na tentativa de conciliar as informações contraditórias, cometem delitos, mentem, demonstram sentimentos e desejos, e chegam até mesmo a sonhar. ${ }^{7}$

Produzidos pelo poder divino ou pelas mãos humanas, por meio da ciência ou da magia, feitos de material orgânico ou mecânico, animados por uma centelha ou por um mecanismo de corda, produtos da imaginação ou da engenhosidade humana, os autômatos colocam sempre a questão de sua diferença com os humanos. Subjacente à interrogação o que é o humano?. residem as indagações sobre o que é a vida? e quem tem o poder de gerála?.

\section{As novas tecnologias de informação e a subjetividade homem-máquina}

A ciência do século XX relaciona-se com essas questões de forma inquietante. Por um lado, ao explicar os mecanismos da vida em termos de interações moleculares e programa genético, a biologia molecular elimina a possibilidade de vitalismo (um princípio de origem desconhecida, uma força ou energia vital intrínseca aos seres vivos que escaparia às leis da física), produzindo uma maquinação do humano a nivel bioquímico. Por outro lado, 
ocorre uma humanização da técnica. As máquinas de última geração são providas de organização, interagem com o ambiente e executam tarefas cognitivas. As tecnologias são invasivas e biocompatíveis, tornando ambiguas as diferenças entre natural e artificial, corpo e mente, orgânico e metálico. É preciso repensar os conceitos de humano e de técnica.

Comecemos pelos humanos. A biologia revela que não há outra explicação para os fenômenos da vida que não seja por reações físico-químicas. As noções de informação, código e programa, quando aplicadas a seres vivos, situam-se no ponto de articulação entre matéria e pensamento, trazendo novos questionamentos sobre a organização e a evolução do mundo vivo.

$\mathrm{Na}$ segunda metade do século XX inúmeras pesquisas de diversas disciplinas se dedicam aos temas da organização dos sistemas vivos e maquínicos. Áreas como filosofia, biologia, neurociências, ciências cognitivas, inteligência artificial e vida artificial defendem idéias distintas e polêmicas sobre o estatuto do humano, do pensamento e da vida. Conceitos fundamentais para a compreensão do humano, como vida, corpo biológico, inteligência, consciência, mente e pensamento têm significados e graus de importância completamente distintos em função das correntes teóricas que os investigam. Por escapar ao escopo e tamanho deste artigo, não apresentamos aqui descrições ou análises de cada termo. O objetivo é somente ressaltar os dois pontos que ajudam a compreender porque estamos nos tornando ciborgues. O primeiro refere-se ao modo como, apesar de defenderem concepções distintas sobre a vida e as relações corpo/cérebro/pensamento, as principais correntes teóricas entendem que não há diferença de natureza entre o ser vivo e a matéria inerte. $O$ geneticista François Jacob sentencia: "Há diferença entre o mundo vivo e o mundo inanimado: diferença de complexidade, não de natureza" (1983, p. 283). O segundo diz respeito ao modo como pensamento e inteligência têm sido dissociados da consciência de si, deixando de ser faculdades exclusivas do humano. Autorizadas pelas ciências biológicas a reconfigurar o corpo como um sistema que processa informações, as novas tecnologias informacionais prometem também remapear os domínios mentais do humano. As ciências cognitivas demonstram que $95 \%$ das ações realizadas pelo pensamento humano são automáticas (LAKOFF e JOHNSON, 1999, p. 13). Surge a idéia de que, se os humanos exibem comportamento inteligente ao realizar tarefas automáticas, nada impede de pensar que outras entidades que agem mecanicamente tenham mentes. Inteligência e cognição não dependem de consciência. Associam-se a comportamento inteligente. ${ }^{8}$ As disputas teóricas sobre as novas relações entre humano, ciência, cultura e tecnologia são acirradas. Afinal, subjacente ao questionamento é preciso estar vivo para pensar?, estão em jogo a subjetividade e a intensidade do ser vivo. Ambos os pontos relacionam-se ao sombreamento das fronteiras modernas - natural/artificial, orgânico/ 
maquínico, interior/exterior, visivel/invisivel - que garantiam a diferença de natureza entre humano, animal e máquina, revelando a interrogação sobre o lugar do humano no mundo hoje.

Se os humanos parecem cada vez mais automatizados, as máquinas, à medida que se desenvolvem, tornam-se capazes de imitar, e depois ampliar, habilidades humanas cada vez mais sofisticadas. Os estudos da cibernética foram os principais precursores da mudança de estatuto das máquinas. Para Norbert Wiener as máquinas atuam de modo semelhante aos organismos biológicos e esse funcionamento baseia-se na troca de mensagens com o ambiente a fim de diminuir a entropia. Hoje, robótica, inteligência e vida artificial buscam conceder às máquinas habilidades cognitivas e sociais e a capacidade de estar vivo. Construídos com o objetivo de compreender o modus operandi do ser humano, nossos robôs são cada vez mais feitos à nossa imagem e semelhança. Uma das novidades nas gerações mais recentes são os robôs situados ou ancorados. Esta nova tendência na robótica busca construir robôs mais autônomos e mais próximos dos organismos vivos. Busca-se desenvolver inteligência e ações cognitivas com base em aparatos sensóriomotores por meio do qual os robôs troquem informações com o meio. Desse modo, a inteligência do autômato é estabelecida em um suporte corporal e leva em conta o histórico das ações do robô ao se confrontar com situações concretas. Um dos robôs mais sofisticados construídos até o momento é Cog. Rodney Brooks, seu criador, o define como um "modelo de robô social que está lenta e metodicamente evoluindo" (Apud MENZEL e D'ALUISIO, 2000, p.64). Brooks espera que um dia $\operatorname{Cog}$ atinja a inteligência de um bebê de seis meses. $\operatorname{Cog}$ foi criado com o objetivo de modelar a inteligência humana em um robô con corpo físico, possibilitando a investigação de temas como desenvolvimento, incorporação física, integração sensório-motora e interação social.

O desenvolvimento tecnocientifico ao produzir uma maquinação do humano e uma humanização da técnica não aponta apenas para as complexas questões fronteiriças sobre onde termina o humano e começa a tecnologia. Indica uma nova relação entre humanos e técnica: a tecnologia é constituinte do humano. Esta lição nos é dada pelas recentes pesquisas das ciências cognitivas e neurociências. Na sociedade atual nossas atividades mais corriqueiras, sejam de caráter orgânico, sensorial, cognitivo ou laborativo, estão tão imbuídas de artefatos tecnológicos que a distinção entre natural e artificial perde a nitidez. O uso de máquinas em atividades laborativas não é novidade. Já há algum tempo, as máquinas invadem nossos lares, locais de trabalho e hospitais para nos ajudar a respirar, andar e ver. Hoje, não se pode negar também sua participação em tarefas cognitivas. Edwin Hutchins cunhou o conceito de cognição distribuida a partir de seu estudo sobre sistemas de navegação em alto-mar (Apud HAYLES, 1999, p.289). O pesquisador demonstra 
que os sistemas de orientação de navios deve-se a interações complexas em um ambiente que envolve humanos e não-humanos. A noção de cognição distribuída refere-se ao modo como a produção e difusão de conhecimentos na atualidade realiza-se como um processo partilhado por humanos e dispositivos tecnológicos (redes de comunicação, programas de computadores, entre outros). $\mathrm{O}$ autor argumenta que cotidianamente participamos de ambientes cuja capacidade cognitiva total excede nosso conhecimento individual, entre eles "carros com sistemas de ignição eletrônica, microondas com chips de computador que ajustam níveis de potência com precisão e máquinas de fax que dialogam com outras máquinas de fax"(Idem). Hutchins conclui que "o homem moderno tem habilidades cognitivas mais sofisticadas do que os homens da caverna, não por serem mais inteligentes, mas por terem construído ambientes de trabalho mais inteligentes" (Idem).

Por fim, a tecnologia oferece novas configurações espaço-temporais, constituindo outras experiências de espacialidade para o humano.

Desde o telégrafo, tornou-se possível separar a informação dos corpos físicos que the davam suporte. Hoje, as interfaces gráficas permitem a imbricação fisica e cognitiva de seres humanos com o computador, gerando um espaço informacional que dilui fronteiras entre fisico e não-fisico, interior e exterior, orgânico e maquínico. As tecnologias de informação permitem imbricações do corpo com as máquinas, ação física com os bancos de memória do computador. O ciberespaço e a realidade virtual são desafios para nós, 188 ocidentais, que pelo menos desde a física newtoniana, estamos acostumados a associar a totalidade da realidade ao espaço físico tridimensional. Mas, a ficção científica sempre explorou configurações espaço-temporais inusitadas: planetas exóticos, universos alternativos, universos paralelos, espaço sideral, hiperespaço, e até mesmo, artérias e veias do sistema sangüíneo. Na década de 80 , as simulações de computador, a rede Arpanet e as janelas de hipertexto já existiam como fenômenos separados, mas só a partir da obra de ficção científica Neuromancer, de William Gibson, publicada em 1984, foram constituídas como um espaço de interação informacional. Foi preciso um escritor de ficção científica para dar unidade, nome e sentido às tecnologias nascentes. Enquanto nosso ciberespaço é uma rede - espaço sem lugar, sem escala e sem tempo -, o ciberespaço de Gibson é campo narrativo, lugar de ação e de circulação. A ficção científica preenche o ciberespaço com subjetividade, espacialidade e temporalidade.

\section{Nossos Outros (II): andróides e computadores}

No decorrer do século XX, à medida que as tecnologias se aprimoram, as histórias sobre os nossos "outros" ficam cada vez mais inquietantes. Com o desenvolvimento da cibernética e da biologia molecular nas décadas de $40 \mathrm{e}$ 50 , os robôs da ficção científica começam a se tornar ainda mais semelhantes 
fisicamente aos humanos - surgem os andróides. O uso atual do termo andróide em geral denota robôs que reproduzem a aparência humana, podendo ser produzidos com substâncias orgânicas ou revestidos com materiais sintéticos que imitam fielmente musculatura e pele. Autênticas reproduções humanas, os andróides são considerados seres mais evoluídos que os robôs, e freqüentemente alcançam niveis de complexidade mental - e até emocional - que rivalizam com os humanos. Os autores tradicionalmente relacionados ao período denominado New Wave produziram obras marcantes sobre andróides e sua relação com humanos. Os andróides descritos por Robert Silverberg em $A$ torre de vidro (1970) não são meras máquinas, possuem alma; não são assassinos tentando destruir a raça humana, mas indivíduos que lutam pelo direito de ser livres (Cf. SILVERBERG, s/d).

Em Blade Runner - o caçador de andróides (1980), Phillip K. Dick desenvolve a questão de se um andróide for construido com a mesma constituição bioquimica de um humano e agir como tal, como diferenciálos? À primeira vista pode parecer que o autor pretende distingui-los pela capacidade empática que os humanos têm e os andróides, não. Como um grande problematizador das relações entre subjetividade, desenvolvimento tecnocientifico e experiências possiveis, Philip K. Dick não se encanta com soluções fáceis e dicotômicas. No livro, a personagem andróide cantora de ópera Luba Luft sugere ao herói Rick Deckard que ao aposentar andróides ele não demonstra nenhum tipo de empatia pelo outro ser, tornando-se portanto um andróide. A questão ética do humano é exposta por Luba Luft: "se um humano extermina um outro ser só porque não possui empatia, ele não está da mesma forma demonstrando ausência de empatia e, portanto, agindo como um andróide? Não se torna igual a ele?" (DICK, 1989, p.115) A impossibilidade de diferenciar humanos e máquinas causa profundo dilaceramento no autor. A ambigüidade perpassa toda a obra. No final do livro, uma grande revelação é anunciada no programa de televisão lider de audiência Buster Amigão: Wilbur Mercer - o Messias vivo da religião mercerismo, principal forma de se provar a empatia - é uma farsa. Encontraram um ator da velha Hollywood que representava seu papel. Se a fusão que ocorre no mercerismo é um embuste, toda experiência de empatia é colocada em questão. A andróide Irmgard Baty expõe o problema: "Isso não é uma maneira de provar que os humanos podem fazer uma coisa que nós não podemos? Isto porque, sem a experiência de Mercer, temos simplesmente a palavra de vocês de que sentem esse negócio de empatia, essa coisa compartilhada, coletiva" (Id, p.228).

Constituídos por caixas gigantescas e opacas que encerram circuitos elétricos indecifráveis e insondá eis, os computadores representam a frieza e a assepsia do cálculo perfeito, isento de emoções. Eles são o ideal máximo de perfeição: desvencilham-se dos inconvenientes do corpo próprio, ao mesmo 
tempo em que, sendo máquinas, reúnem atributos de lógica, inteligência e razão puras. O robô e o andróide ainda são feitos à imagem e semelhança do homem, mas o computador, destituído de aspectos antropomórficos, parece tocar diretamente o divino. Em geral, os computadores da ficção científica são inteligências artificiais puras que prescindem da forma corporal dos robôs, mantendo apenas os mecanismos constituintes do cérebro. Freqüentemente desejam evoluir à condição divina. Ao se posicionarem no limiar do humano, robôs, andróides e computadores colocam a questão de o quê define o humano: o corpo físico, a constituição biológica, as emoções, a percepção sensório-motora, o pensamento, a capacidade de criar vida, e que relação existe entre esses elementos.

No século XX, quando robôs e computadores passam a realizar tarefas cognitivas, um novo matiz é adicionado à problematização dos seres artificiais. Às questões o que é a vida? e quem tem o poder de gerá-la?, soma-se a intrigante pergunta $o$ que podem os seres criados artificialmente?, trazendo para a vida real a tensão do par criador/criatura. À primeira vista a criação de vida artificial equilibra-se sobre a tênue linha que separa o desejo humano de alcançar a força prometéica do medo de que a criatura nos supere. Mas, o medo e o desejo despertados pela criação de vida artificial pertencem ao mesmo campo de sentidos, uma vez que se o humano alcançar a força prometéica ele estará rivalizando com o seu Criador. A vida artificial parece ser um terreno extremamente proficuo para uma inquietação filosófica das mais angustiantes: a própria condição de existência humana. Mais que interrogar, os autômatos desafiam o humano, o vigor de seu saber e os limites de sua intervenção na natureza.

Vimos como as novas tecnologias informacionais dissolvem as fronteiras ontológicas modernas. Agora veremos que as barreiras epistemológicas também não saem ilesas.

\section{Simular: um método entre a realidade e a ficção}

O computador tornou possível o uso de procedimentos de síntese. Diferente do método analítico - em que a pesquisa começa com o comportamento de interesse e decompõe (analisa) o todo em suas partes constituintes-, a sintese inicia com as partes constituintes, colocando-as juntas na tentativa de sintetizar o comportamento de interesse. A partir de descrições pormenorizadas de componentes e leis de comportamento mecânico, elétrico e químico, o computador calcula todas as possibilidades de variação do sistema, permitindo criar todos os fenômenos possiveis, existentes ou não. Sintetizar é mais que reproduzir em laboratório os processos naturais, é criar objetos e substâncias que não existem na natureza. Sintetizar é criar mundos possíveis. Um exemplo interessante é o do antibiótico sintético Zyvox, desenvolvido para combater as bactérias mutantes e resistentes aos mais potentes antibióticos existentes 
até então. Os cientistas forneceram ao computador todas as informações disponiveis sobre a biologia dos micróbios. Tomando por base os "pontos fracos" das bactérias, o computador sinulou inúmeras substâncias inexistentes na química e as testou virtualmente, até chegar à linezolida. Totalmente sintética, a molécula de linezolida jamais foi vista por um microorganismo: sua aparição surpreende as bactérias que invade, destruindo-as sem que possam se defender (LUCIRIO, 2000, p. 78). A simulação é intrinsecamente um método entre a realidade e a ficção. Mas, simular e criar modelos não são procedimentos novos. A originalidade também não está em fabricar artefatos e instrumentos que não existem na natureza. A novidade consiste no uso das técnicas de engenharia como procedimento científico ${ }^{1}$ e na possibilidade de gerar, modificar, clonar e hibridizar seres vivos, intervindo inclusive sobre nosso patrimônio genético, até então fora de alcance de nossas ações. Ao tornar imprecisas as fronteiras entre o fisico e o não-físico, o natural e o artificial, as biotecnologias e a engenharia genética prometem remodelar o mundo e o ser vivo com um vigor sem precedentes. Talvez este seja o ponto polêmico: a fisica e a química modernas "desmistificaram" os fenômenos naturais ao revelar seus segredos físico-químicos, mas a biologia ao sustentar a tese do vitalismo manteve a vida como locus de um naturalismo dogmático. A intervenção sobre o código genético parece fornecer os segredos do conhecimento proibido, permitindo ao homem rivalizar com o Criador (ou Mãe-natureza ou Seleção Natural). Assim como o Dr. Rossum, de R.U.R., o cientista hoje sintetiza substâncias "que não ocorreram à Mãe-Natureza", e reivindica a co-autoria do mundo junto a ela. Milho híbrido, rato com uma orelha humana nas costas, macaco com gene de água-viva e a ovelha clonada Dolly, parecem ter escapado do clássico A ilha do Dr: Moreau, escrito por H.G.Wells em 1896. No romance de Wells, o cientista realiza transplantes de órgãos e pele entre humanos e animais (Cf. WELLS, 1989).

A simulação por computador inspirou o surgimento de uma abordagem sintética para a biologia - a vida artificial. Para os pesquisadores desta área (LANGTON, 1996), seu campo de estudos não precisa se restringir à tentativa de recriar os fenômenos biológicos existentes: está livre para explorar a natureza tal como poderia ter sido. A vertente forte acredita na possibilidade de se criar modelos tão parecidos com a vida que deixariam de ser modelos e se tornariam exemplos de vida eles próprios. A idéia foi posta em prática por Tomas Ray. Os organismos digitais de Ray "vivem" num espaço chamado Tierra, um computador virtual simulado dentro de um computador real (RAY, in: GIANNETTI, 1998, p. 253-263). Na ficção científica este tema apareceu em 1964 no livro Simulacron - 3, de Daniel F. Galouye (1968), que serviu de base ao filme $13^{\circ}$ andar (1999, Josef Rusnak). David Pringle, autor de The ultimate guide to science fiction, define a obra como uma história de realidade virtual à frente de seu tempo. Para nós, a existência de pesquisas como a de Thomas 
Ray, é mais um sintoma de que as tecnologias informacionais, ao problematizar fronteiras modernas, trazem para o seio da ciência questionamentos antes restritos à fiç̧ão científica. De um lado, não há evidência de que as realizações de computador possam incorporar a complexidade subjetiva dos seres vivos superiores. Por outro lado, as "realizações de computador" interrogam sobre como agir se os organismos digitais, tais como os personagens simulados de Simulacron 3, começarem a se sentir vivos. Uma vez que conhecem apenas o universo virtual, este pode lhes parecer suficientemente real. Um aprofundamento conceitual sobre a vida artificial que escapa aos objetivos deste estudo conduziria a questionamentos sobre o que é a vida, quem está vivo, o que é realidade, entre outros. O que evidentemente remete à incômoda possibilidade de existência de outras configurações espaço-temporais desconhecidas por nós, contudo mais reais que a nossa, das quais seríamos meras simulações. Esta tese que soa como especulação leviana das histórias de ficção científica foi proposta de modo semelhante pelos físicos Edward Fredkin e Stephen Wolfram, que acreditam que a realidade é um programa que roda em um computador cósmico (Apud HAYLES, 1999, p. 11).

\section{O devir ciborgue}

As complexas relações entre corpo e mente, as imbricações entre humanos e tecnologia, as novas possibilidades de viagens - dentro da máquina e no

192 espaço sideral -, a contração de presente e futuro, as associações entre fiç̧ão e realidade e a capacidade de intervir sobre a vida levaram o sujeito moderno a uma crise de referência. A discussão sobre o novo conceito de humano, as novas potencialidades do corpo e da mente, e as novas condições de subjetividade tem encontrado solo fértil na figura do ciborgue.

Produtos da imbricação entre humanos e autômatos, as misturas entre corpos biológicos e artefatos mecânicos, inteligências naturais e memórias artificiais recebem o nome de seres biônicos ou ciborgues. $O$ mito do ciborgue se tornou familiar à cultura ocidental desde o início do século XX. A palavra ciborgue - do inglês cyborg - é a abreviatura para organismo cibernético (cybernetic organism). Donna Haraway em seu já clássico Um manifesto para os ciborgues define ciborgue como "um organismo cibernético híbrido: é máquina e organismo, uma criatura ligada não só à realidade social como à ficção. (...) criaturas simultaneamente animal e máquina que habitam mundos ambiguamente naturais e construídos" (1994, p. 243-4).

O devir-ciborgue significa que, hoje, o modo como construímos nossa subjetividade, nossa experiência no mundo, é intimamente relacionado à tecnologia. Tradicionalmente, o conceito de humano é construído a partir de sua diferença com a alteridade. Robôs, andróides, computadores e outros monstros estão no limiar do humano, são o outro do eu. O ciborgue incorpora 
a alteridade seguindo a lógica do fantasma que aponta para a diferença entre $e u$ e $e u$. A fusão entre homem e máquina explicitada pelo ciborgue revela a nova natureza da técnica: as tecnologias de informação e a comunicação mediada por computador são modos de constituição do humano.

As definições de ciborgue mais recentes incluem todo tipo de intervenção tecnológica, seja o uso de medicamentos (restauradores da saúde, psicotrópicos ou preventivos contra doenças), seja a conexão com instrumentos de mecânica, eletrônica ou informática. Para Gray, Mentor e Figueroa-Sarriera:

Qualquer pessoa com um órgão, membro ou suplemento artificial (como um marca-passo), qualquer um reprogramado para resistir a doenças (imunizado) ou drogado para pensarl comportar-se/sentir-se (psicofarmacologia) melhor é tecnicamente um ciborgue. $(1995$, p.2)

Katherine Hayles defende uma visão semelhante:

Ciborgues realmente existem; estima-se que cerca de $10 \%$ da população atual dos E.U.A. são ciborgues no sentido técnico, incluindo pessoas com marca-passos eletrônicos, juntas artificiais, sistema automático de administração de medicamentos, lentes implantadas na córnea, e pele artificial. Um percentual muito maior participa em ocupações que os torna ciborgues metafóricos. incluindo o tecladista de computador unido a um circuito cibernético com a tela, o neurocirurgião guiado por um microscópio de fibra ótica durante uma operação e o adolescente que brinca com videogames no salão de diversões eletrônicas de seu bairro (HAYLES, in: GRAY, MENTOR e FIGUEROASARRIERA, 1995, p. 322).

O ciborgue torna-se realidade a partir de rupturas de fronteiras ontológicas construídas sobre - o que acreditávamos ser - sólidas fundações culturais, históricas e epistemológicas.

O marco zero dessas rupturas se refere à dissolução de fronteiras entre humano e animal, inaugurada pela teoria da evolução de Charles Darwin. O cientista desfere um golpe vital na superioridade da espécie humana ao enunciar que o ser humano evoluiu de animais e defender o acaso como mecanismo principal na variação entre as espécies ( $C f$. DARWIN, 2002). Darwin não se restringe ao plano fisiológico: explora as semelhanças das expressões de emoções humanas e animais, concluindo que os principais atos expressivos exibidos pelo homem e pelos animais são inatos ou hereditários ( $C f$. DARWIN, 2000).

A principal ruptura subjacente à lógica atual é o esmaecimento de fronteiras entre orgânico e maquínico, natural e artificial, animado e inanimado. Como vimos, a continuidade entre o ser vivo e a matéria inerte foi impulsionada pelas 
pesquisas da biologia molecular ao descobrir que os níveis mais elementares do ser vivo são formados pelos mesmos compostos químicos da matéria inorgânica.

O segundo rompimento de fronteiras refere-se aos estudos nas áreas de ciências cognitivas, inteligência artificial e filosofia que têm se esforçado em mostrar que o pensamento e a inteligência não dependem da consciência de si. Atividades como tomada de decisões e raciocínio lógico-matemático são executadas por máquinas inteligentes, deixando de ser atividades exclusivas do humano. As fronteiras entre seres biológicos e maquínicos, corpo e pensamento, matéria viva e inerte são colocadas em movimento.

Assim como a ficção científica, o ciborgue dilui as fronteiras ontológicas e epistemológicas modernas, permitindo que o caráter múltiplo da vida e da experiência aflore. $O$ ciborgue convida à reflexão sobre o humano $e$ as novas experiências possibilitadas pela interação com a tecnologia. Um exemplo ficcional ajuda a compreender esta idéia. Em Robocop - o policial do futuro (Paul Verhoven, 1987), o policial Alan Murphy - após ser morto em confronto com bandidos - tem o pouco que restou de seu corpo usado para a constituição de um superpolicial ciborgue: o Robocop. À medida que a história se desenrola, o ciborgue reconstitui as lembranças de Murphy por meio de imagens biológicas e eletrônicas. Ao se deparar com um dos bandidos que matou o policial, Robocop o reconhece; é a manifestação da promessa de humano na máquina. $\mathrm{Na}$ fiç̧ão, a tecnologia não elimina o humano. $\mathrm{O}$ ciborgue não é negação do

194 humano. O ciborgue é ocasião de exploração das novas experiências tornadas possiveis pela associação com a tecnologia. A junção com a máquina revigora as capacidades fisicas, sensoriais e cognitivas, permitindo a emergência de novas experiências subjetivas.

No entanto, a aceitação do ciborgue como devir humano não é nenhum consenso. Para muitos, a mistura com a máquina é perda de nossa humanidade. Para os detratores do ciborgue, vale lembrar as pesquisas de Scott Bukatman e Bruce Mazlish - autores que enfatizam que a produção de ferramentas como modo de interagir com o ambiente é definidora de nossa espécie. Bukatman (1998) sugere que as novas concepções de humano devem situar homens e tecnologia como co-extensivos, co-dependentes e definidos mutuamente. Mazlish (1993) revela que sob os questionamentos atuais sobre a natureza do humano e da técnica reside um longo percurso de co-evolução entre os homens e suas máquinas. Mas, então, se a relação homem-máquina é "natural", porque chamar o humano de ciborgue? Justamente para destacar a singularidade do pensamento contemporâneo. A produção de ferramentas pode ser definidora de nossa espécie, mas esta forma de pensar é específica da Atualidade. Apenas hoje consideramos que a interrogação do humano é indissociável da tecnologia.

Podemos acolher ou rejeitar o devir ciborgue. $O$ que não parece possível é se furtar de refletir sobre a relação homem-máquina hoje. O sonho é que o 
ciborgue seja um convite a novas experiências e à construção de pontos de vista subjetivos em que o parentesco com animais e máquinas promova a potencialização da vida e amplie as possibilidades da aventura humana no mundo. O pesadelo é que todo o potencial tecnológico permaneça sob domínio dos países ricos e das megacorporações. Como o que está em jogo é a possibilidade de gestão coletiva das novas tecnologias e o estatuto do humano e do ser vivo, é preciso estar atento para que a reflexão sobre as experiências tornadas possíveis pelas novas tecnologias não se restrinja às pesquisas acadêmicas e às histórias de ficção científica. A narrativa sobre a aventura da humanidade não está concluída. Nós escreveremos seus próximos capitulos. Cabe a nós decidir se seremos zumbis, robocops ou qualquer devir-outro que desejarmos. Como diz o menino Hogart para o robô no desenho animado $O$ Gigante de Ferro (Warner, 1999):

Você é o que escolhe ser.

\section{Bibliografia}

ASIMOV, Isaac. No mundo da fiç̧ão científica. Rio de Janeiro: Francisco Alves, 1984.

BUKATMAN, Scott. Terminal Identity: the virtual subject in post-modern science fiction. 4 ed. Duke University Press: 1998.

CAPEK, Karel. "R.U.R.". In: Os melhores contos de FC de Júlio Verne aos astronautas. Lisboa: Livros do Brasil, s/d. (Coleção Argonauta, $\mathrm{n}^{\circ} 100-$ volume duplo comemorativo).

CLUTE, John, NICHOLLS, Peter. The Encyclopedia of Science Fiction. New York: St. Martin's Griffin, 1995.

DARWIN, Charles. A expressão das emoções no homem e nos animais. São Paulo: Companhia das Letras, 2000.

. Origem das espécies. 4 ed. Belo Horizonte: Itatiaia, 2002.

DELEUZE, Gilles. Diferença e repetição. Rio de Janeiro: Graal, 1988.

DENNETT, Daniel C. A perigosa idéia de Darwin. Rio de Janeiro: Rocco, 1998. . Kinds of minds. Nova York: Basic Books, 1996.

DESCARTES, René. Discurso do método. São Paulo: Nova Cultura1, 1996. DICK, P. K. O caçador de andróides. 4 ed. Rio de Janeiro: Francisco Alves, 1989.

DOMINGUES, Diana. A arte no século XXI-a humanização da tecnologia. São Paulo: Unesp, 1997.

FOUCAULT, Michel. História da Sexualidade 2: o uso dos prazeres. 6 ed. Rio de Janeiro: Graal, 1984.

GIBSON, William. Neuromancer. São Paulo: Aleph, 1991.

GRAY, Chris Hables, MENTOR, Steven, and FIGUEROA-SARRIERA, Heidi J. "Cyborgology: Constructing the Knowledge of Cybernetic Organisms". In: 
The Cyborg Handbook. New York e Londres: Routledge, 1995.

HARAWAY, Donna. "Um manifesto para os cyborgs: ciência, tecnologia e feminismo socialista na década de 80". In: HOLLANDA, Heloísa Buarque de. Tendências e Impasses: o feminismo como crítica da cultura. Rio de Janeiro, 1994.

HAYLES, Katherine. How we became posthuman. Chicago: The University of Chicago Press, 1999.

JACOB, François. A lógica da vida. Rio de Janeiro: Edições Graal, 1983.

LAKOFF, George, JOHNSON, Mark. Philosophy in theflash. Nova York: Basic Books, 1999.

MAZLISH, Bruce. The fourth discontinuity: the co-evolution of humans and machines. Nova Haven, Londres: Yale University Press, 1993.

MENZEL, Peter, D'ALUISIO, Faith. Robo Sapiens: evolution of a new species. Cambridge: MIT, 2000.

MORAVEC, Hans Paul. Mind Children. Cambridge: Harvard University Press, 1988.

OLIVEIRA, Fátima Cristina Regis Martins de. Nós, ciborgues: a fição cientifica como narrativa da subjetividade homem-máquina. Rio de Janeiro: UFRJ/Escola de Comunicação, 2002. xii, 227 p.

POE, Edgar Allan. "O jogador de xadrez de Maelzel". In: Histórias Extraordinárias. São Paulo: Abril Cultural, 1981.

POHL, Frederik. "The politics of prophecy". In: HASSLER, Donald M., WILCOX, Clyde (ed.). Political Science Fiction. University of South Carolina Press, 1997.

PRINGLE, David. The ultimate guide to science fiction. 2nd ed. Cambridge: Scolar Press, 1995.

SHELLEY, Mary. Frankenstein. Rio de Janeiro: Ediouro, s/d.

SILVERBERG, Robert. A torre de vidro. Lisboa: Publicações Europa-América, s/d. (Coleção Ficção Científica, no 13)

SMITH, Nicholas D. (ed.) Philosophers look at science fiction. Chicago: Nelson-Hall, 1982.

STELARC. "Das estratégias psicológicas às ciberestratégias: a protética, a robótica e a existência remota". In: DOMINGUES, Diana (org.). A arte no século XXI: a humanização das tecnologias. São Paulo: Unesp /Edusp, 1997.

WELLS, Herbert George. A ilha do Dr. Moreau. 2 ed. Rio de Janeiro: Francisco Alves, 1989. (Coleção Mestres do Horror e da Fantasia)

. A máquina do tempo. 3 ed. Rio de Janeiro: Francisco Alves, 1989.

(Coleção Mestres do Horror e da Fantasia)

\section{Periódico:}

LUCIRIO, Ivonete, MENAI, Tânia. Bactérias em pânico. Superinteressante, 
São Paulo, jun de 2000. p. 78.

\section{Filmes:}

13o. Andar / The Thirteenth Floor: EUA: Columbia / Tri-Star Studios, 1999.

Dir.: Josef Rusnak. 100 min.

O gigante de ferro/The lron Giant. EUA: Warner, 1999. Dir: Brad Bird. 86 min. Robocop, o policial do futuro/Robocop. EUA: Orion Pictures, 1987. Dir.: Paul Verhoven. $103 \mathrm{~min}$.

\section{Notas:}

' Steve Mann é um dos pioneiros no uso de acessórios tecnológicos para alterar a percepção da realidade. Desde 1981, Mann utiliza uma câmera de vídeo no olho direito - um eyetap - para amplificar e intensificar as percepções de seu corpo. A percepção visual que Mann tem do mundo é inteiramente mediada pela câmera. Cf.Filme Cyberman / Cyberman. EUA, 2000. Dir.: Peter Lynch. Mostra Rio, 2001. Na Internet: http://cbc.ca/cyberman.

${ }^{2}$ Em Mind Children (Cambridge: Harvard University Press, 1988) Hans Paul Moravec especula sobre a possibilidade de se fazer cópias da mente e, até mesmo mesclar memórias de pessoas diferentes em uma mesma mente. $\mathrm{O}$ autor de ficção científica Robert Silverberg já havia explorado essas possibilidades em 1969, no romance To live again (Warner Books) no qual os vivos disputam as mentes gravadas de gênios falecidos para serem mescladas às suas próprias, na condição de consciências secundárias.

${ }^{4} \mathrm{O}$ livro de Charles Taylor Sources of the self (Cambridge: Harvard University Press, 1996) é uma referência importante para o aprofundamento desta questão. ${ }^{5} \mathrm{O}$ desenvolvimento completo deste argumento está na tese Nós, ciborgues: a fiç̧ão cientifica como narrativa da subjetividade homem-máquina.

Rio de Janeiro: UFRJ/Escola de Comunicação, 2002, cap. 3.

${ }^{6} \mathrm{Cf}$. OLIVEIRA, Fátima Cristina Regis Martins de. Nós, ciborgues: a fiç̧ão cientifica como narrativa da subjetividade homem-máquina. Rio de Janeiro: UFRJ/Escola de Comunicação, 2002, cap. 4.

${ }^{7} \mathrm{Na}$ tese, os contos Robbie, O pequeno robô desaparecido, Razão e Sonhos de robô, todos de Isaac Asimov, fornecem o cenário para o desdobramento dessas questões

${ }^{8}$ No texto integral da tese, esta idéia é desenvolvida com o apoio dos trabalhos de Daniel Dennett, em particular: DENNETT, Daniel. Kinds of minds. Nova York: Basic Books, 1996. DENNETT, Daniel C. A perigosa idéia de Darwin. Rio de Janeiro: Rocco, 1998.

${ }^{9}$ Herbert Simon explica que historicamente e tradicionalmente há uma divisão de métodos entre as ciências ditas naturais e a engenharia e o design (ciências artificiais): as primeiras se ocuparam de explicar as coisas naturais - como são e como funcionam. Coube às escolas de engenharia estudar as coisas artificiais 
- como projetar e fazer artefatos com as propriedades desejadas. Cf. Sciences of Artificial. $3^{\text {rd }}$. ed. Cambridge: The MIT Press, 1999, p. 111.

\section{Palavras-chave}

1. Subjetividade

2. Tecnologia

3. Ficção científica

4. Ciborgue

5. Ciberespaço 